\title{
The TCVD Growth of CNTs over Copper-Silver-Palladium Nanoparticles Prepared by DC Magnetron Sputtering
}

\author{
S. ReZAeE ${ }^{a, *}$, M. MARDANi ${ }^{b}$ And R. ShakOURY ${ }^{c}$ \\ ${ }^{a}$ Department of Physics, Kermanshah Branch, Islamic Azad University, Kermanshah, Iran \\ ${ }^{b}$ Vacuum Technology Research Group, ACECR, Sharif University Branch, Tehran, Iran \\ ${ }^{c}$ Department of Physics, Faculty of Science, Imam Khomeini International University, Qazvin, Iran \\ (Received October 17, 2019; revised version December 25, 2019; in final form January 28, 2020) \\ In this study, we investigate the use of catalytic copper-silver-palladium substrates for the growth of multi- \\ walled carbon nanotubes via the thermal chemical vapor deposition. These layers are comprised of nanocrystals of \\ $\mathrm{Cu}_{2} \mathrm{O}, \mathrm{CuO}, \mathrm{Ag}, \mathrm{Pd}, \mathrm{Cu}$, and $\mathrm{PdO}$ and were grown using a DC magnetron sputtering method. Scanning electron \\ microscopy characterizations confirmed the significant growth of carbon nanotubes on the catalytic layer. A com- \\ parison of the growth of nanotubes indicated that the thickness of the catalytic layers has a significant impact on \\ the quality and the diameter of the carbon nanotubes. Two major peaks were seen in the Raman spectrum. The \\ formation of graphite multiwalled nanotubes and the presence of defects in the graphene-like hexagonal disordered \\ carbons were confirmed by the appearance of the $G$ band (graphite band) and the $D$ band (disorder-induced band), \\ respectively. The ratio of the intensities of these bands, $I(G) / I(D)$, indicated a good graphite structural quality.
}

DOI: 10.12693/APhysPolA.137.1075

PACS/topics: DC magnetron sputtering, TCVD, carbon nanotubes, nanocatalyst

\section{Introduction}

Carbon nanotubes (CNTs) exhibit outstanding properties, including high mechanical and chemical stabilities, enhanced mechanical strength, elevated electrical conductivity, and high aspect ratio, which have attracted increasing attention in different fundamental and applied fields.

Since the discovery of carbon nanotubes, many efforts have been devoted to enhance the growth of these nanostructures and control their properties for specific applications. One of the principal goals is the production of allotropes with coiled or helical structures, aligned and straight arrangements, Y-junctions or bamboo-shaped carbon nanostructures [1].

Three principal methods are mostly used to produce CNTs: arc discharge [2], laser ablation [3], and chemical vapor deposition (CVD) $[4,5]$. In the CVD method, a hydrocarbon is pyrolized over a metal catalyst. A wide range of methods uses the generic name CVD e.g., thermal CVD (TCVD), hot-filament CVD (HFCVD), and plasma-enhanced CVD (PECVD) [4-7]. The advantages of the CVD method over other CNTs production techniques are its high efficiency, low cost, high purity of the final CNTs, and selective growth of the CNTs. The growth of CNTs using the CVD method involves a twostep procedure. In the first step, the nanostructured

*corresponding author; e-mail: saharrezaee593@iauksh.ac.ir catalytic layers are prepared. Then, CNTs are grown on these layers. In this method, the synthesis parameters such as pressure, hydrocarbon source, growth temperature, substrate type, and the properties of the catalysts like composition, morphology, and the employed preparation technique [8] have significant effects on the characteristics of the final product. These include its crystallization, morphology, surface density, and diameter distribution. On the other hand, the TCVD is one of the most interesting methods to synthesize the CNTs due to its ability to produce large quantities of CNTs.

The physical and chemical properties of the CNTs, such as the electrical conductivity, are strongly dependent on the chirality and the single-wall or multiwall character of the nanotubes, obtaining metallic or semiconductor properties. CNTs are used as probe tips for very high-resolution scanning probe microscopy due to their mechanical properties, including elasticity and strength. By improving the thermal and thermomechanical properties, these materials can be used as nanocomponents of polymeric nanocomposites owing to their thermal conductivity and their robust mechanical properties. Moreover, both single- and multiwall CNTs are suitable to be used as electrodes in capacitors and batteries $[9,10]$.

Since low particle concentrations are required, which can be obtained by low-cost techniques, the use of metal nanoparticles (NP) as nanocatalyst (NC) is attractive for TCVD procedure in the CNT fabrication [11]. A hightemperature medium is required for the CNT formation, with nanotubes directly grown on the substrate. Thus, this procedure is just applicable to fabricate CNTs from carbon sources on specific substrates. 
As the catalyst particles are preferential places for the CNT growth, the particle density and diameter of the catalytic NPs are significant factors that govern the growth and characteristics of the CNTs.

The study of the catalytic properties of metal nanoparticles (NPs) as one of the main fields of nanoscience and nanotechnology is significantly increasing [12]. Transition-metal NPs have been considered in current investigations of catalysis due to their high surface/volume ratio and high surface energy, making the surface atoms much more active $[13,14]$. Few studies have been reported on the catalytic properties of Pd NPs compared with other transition metals [8, 15-17]. CNTs grown on the $\mathrm{Pd}$ nanostructures exhibit potential applications in some technological areas, including field emission devices, hydrogen sensors, and hydrogen gas storage [18, 19].

Some metals such as aluminum and copper have a weak catalytic effect. However, they are used due to their impact on the carbon penetration and acceleration of the rate of growth in carbon nanotubes. Copper oxide compounds such as $\mathrm{CuO}$ and $\mathrm{Cu}_{2} \mathrm{O}$ have been found as interesting catalysts to be used in electronic connections and alloy corrosions, among others [20-22]. Hence, metal nanoparticles are promising catalysts for different reactions. In addition, due to their high ionization and large surface area, metal oxide nanoparticles could have unusual crystallography and high surface reaction sites [23]. Since multi-elemental layers have better catalytic properties than single-elemental layers, the study of the catalytic behavior of binary and ternary alloys of these metals can be used to enhance the catalytic behavior and to improve morphology, size, quality, and growth mode of nanotubes.

In previous investigations [24, 25], thin films formed by copper-silver-palladium nanostructures were prepared and studied by means of the direct-current magnetron sputtering method $[24,25]$. In the present study, we investigate the potential use of these films as catalysts for the TCVD of CNTs using acetylene gas as the source of carbon. The effect of thickness of catalytic layers and catalyst particle size on diameter, density, and morphology of CNTs was examined. Moreover, scanning electron microscopy (SEM), transmission electron microscopy (TEM), and the Raman spectroscopy analyses were also used to characterize the carbon nanotubes.

\section{Materials and methods}

\subsection{Materials and experimental procedure}

In this report, the DC magnetron sputtering method was employed to prepare copper-silver-palladium nanostructure. In the operating deposition system, the vacuum ambient was provided with two turbo and rotary pumps, and two electrodes of different areas were located in the chamber. One of them was grounded and the other, the target electrode, was attached to the DC source with a diameter of $89 \mathrm{~nm}$. The substrates were

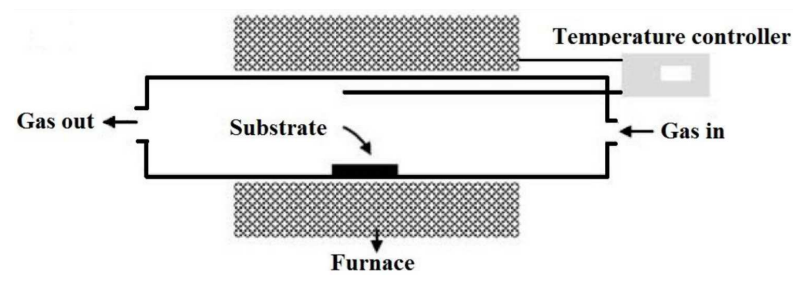

Fig. 1. Schematic representation of the used TCVD system.

placed at the grounded electrode while the distance between the cathode and the anode was maintained approximately at about $7 \mathrm{~cm}$. Argon gas was applied in the sputtering process and an $\mathrm{Ag}-\mathrm{Cu}-\mathrm{Pd}$ target and silicon substrates were utilized. The turbo and rotary pumps were used to vacuum the chamber to the basic pressure of $1.33 \times 10^{-3} \mathrm{~N} / \mathrm{m}^{2}$ before the film deposition. The chamber pressure was elevated to $3.86 \mathrm{~N} / \mathrm{m}^{2}$ with argon gas while a DC power was utilized. (400) silicon substrates with the dimensions of $1 \mathrm{~cm} \times 2 \mathrm{~cm}$ were used for the deposition of $\mathrm{Ag}-\mathrm{Cu}-\mathrm{Pd}$ thin film under the following experimental conditions. The film deposition was carried out at room temperature $(297 \pm 1 \mathrm{~K})$ power of $30 \mathrm{~W}$, and pressure of $3.86 \mathrm{~N} / \mathrm{m}^{2}$. The deposition process was performed with three deposition times of 16,20 , and $24 \mathrm{~min}$, resulting in films with thicknesses of 34.8 , 40, and $46 \mathrm{~nm}$, respectively. A Technor Alpha-Step 500 surface profiler [24, 25] was used to measure the thickness of $\mathrm{Ag}-\mathrm{Cu}-\mathrm{Pd}$ layer. Then, the sputtered $\mathrm{Ag}-\mathrm{Cu}-\mathrm{Pd}$ thin film was employed as a catalyst base to grow the CNTs in the thermal chemical vapor deposition system. After removing impurities and adhering particles from a quartz tube at a temperature of $800^{\circ} \mathrm{C}$ using a temperature controller with the step of $15^{\circ} \mathrm{C}$ per min, nanocatalytic thin films were inserted inside a quartz tube reactor. Then, for the growth of carbon nanotubes, the system temperature was set at $780^{\circ} \mathrm{C}$, and the samples were placed inside the quartz tube for $20 \mathrm{~min}$. After that, acetylene gas with a flow of $60 \mathrm{sccm}$ and low nitrogen gas were utilized as the carbon source and carrier gas, respectively. It should be noted that the system temperature first dropped and then began to increase. After $20 \mathrm{~min}$, this temperature rose to $800^{\circ} \mathrm{C}$. After this time, the flow of hydrocarbon gas was cut off and the argon gas entered in the system to cool the products in its presence. With a drop in the system temperature to $200^{\circ} \mathrm{C}$, the samples were taken out of the quartz tube. The schematic of the TCVD system to synthesize the CNTs consisting of a thermocouple, a reactor, a tube furnace, a gas source, and a substrate (the catalyst place) is shown in Fig. 1.

\subsection{Characterization of the thin films}

The structural properties of nanocatalytic thin films have been investigated by X-ray diffraction (XRD) in previous articles [24, 25]. The grown CNTs and the nanocatalytic thin films were characterized by SEM (FE-SEM, 
TABLE I

Details and ID of the prepared samples. The target was $\mathrm{Ag}-\mathrm{Cu}-\mathrm{Pd}$, and sputtering parameters were: basic pressure $1.33 \times 10^{3} \mathrm{~N} / \mathrm{m}^{2}$, work pressure $3.86 \mathrm{~N} / \mathrm{m}^{2}$, and power $30 \mathrm{~W}$

\begin{tabular}{c|c|c}
\hline \hline ID & $\begin{array}{c}\text { Sputtering } \\
\text { time [min] }\end{array}$ & Thickness [nm] \\
\hline$\# 1$ & 16 & 34.8 \\
$\# 2$ & 20 & 40.0 \\
$\# 3$ & 24 & 46.0
\end{tabular}

Hitachi S-4160microscope) and the Raman spectroscopy (Thermo Nicolet Almega Dispersive Micro-Raman). The conditions of prepared samples are given in Table I.

\section{Results and discussion}

The SEM images of the catalytic thin films deposited with different thicknesses are shown in Fig. 2. It is evident from these images that small nanosize grains constitute the surface of the $\mathrm{Ag}-\mathrm{Cu}-\mathrm{Pd}$ alloy thin films. These nanoparticles are rather spherical, and are distributed with a specific pattern on the film surface with fractal characteristics [25]. Also, these films, as it was studied in previous works, are formed by nanocrystals of $\mathrm{Cu}_{2} \mathrm{O}$, $\mathrm{CuO}, \mathrm{Ag}, \mathrm{Pd}, \mathrm{Cu}$, and $\mathrm{PdO}[25,26]$.

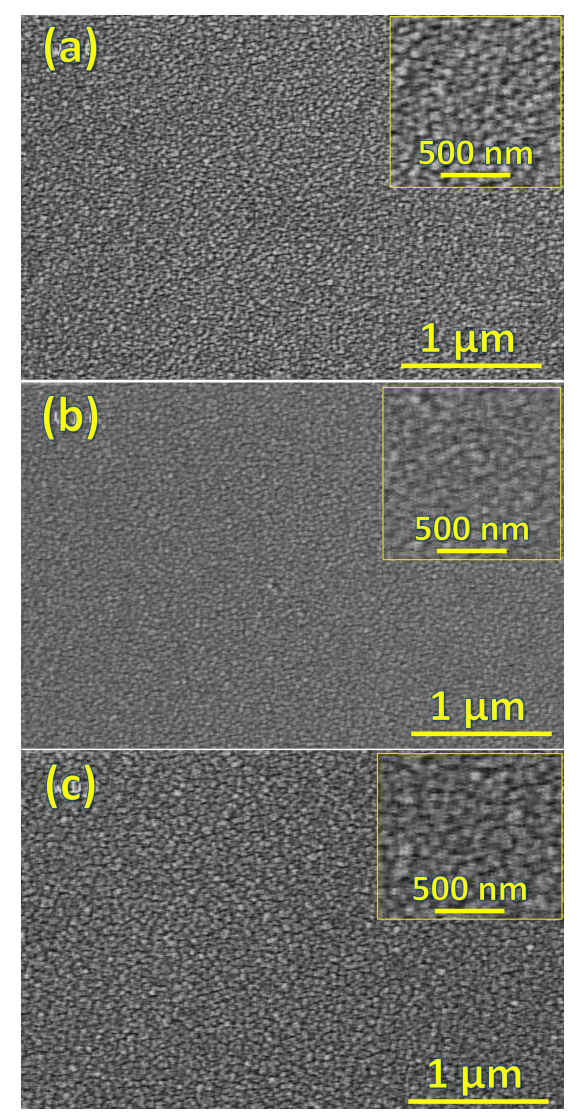

Fig. 2. SEM images of the catalytic thin films: (a) sample \#1, (b) sample \#2 and (c) sample \#3.
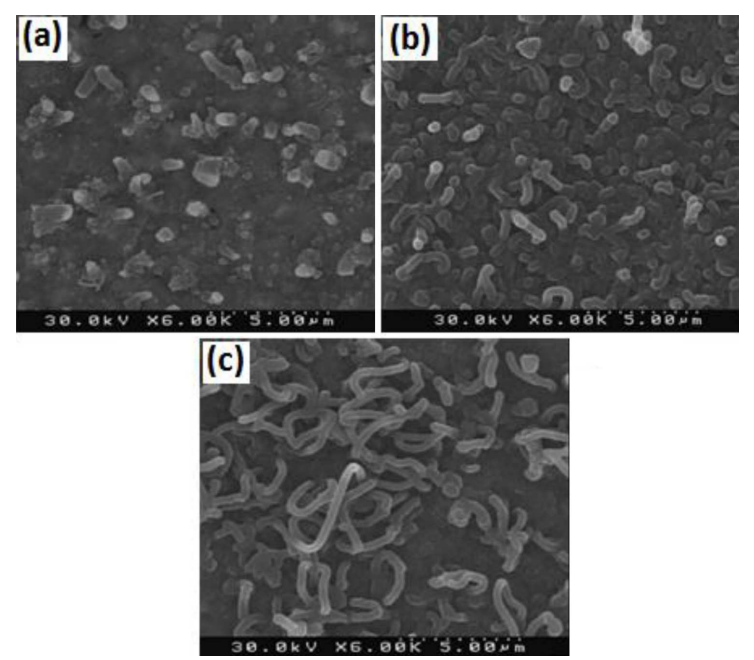

Fig. 3. SEM image of produced CNTs at different thicknesses of catalytic layers: (a) sample 1, (b) sample 2 and (c) sample 3.

SEM images confirm the catalytic properties of coppersilver-palladium thin films to grow nanotubes. Figure 3 shows SEM images of the CNTs grown on $\mathrm{Ag}-\mathrm{Cu}-\mathrm{Pd}$ thin films with thicknesses of $34.8,40$, and $46 \mathrm{~nm}$, respectively. The distributions of the CNTs diameters obtained from Fig. 3 are displayed in Fig. 4, which are fitted to Gaussian curves showing a relatively uniform distribution.

The median diameter of the nanotubes were 350,260 , and $325 \mathrm{~nm}$ for samples 1, 2, and 3, respectively. Since the diameter of the single-wall nanotubes is between one and ten nanometers, it is inferred that only multiwalled nanotubes were grown. On the other hand, the nanotube diameters are around one order of magnitude larger than the diameters of the catalytic nanoparticles. The nucleation sites are probably not constituted by a single nanoparticle but by several nanoparticles with different composition $\left(\mathrm{Cu}_{2} \mathrm{O}, \mathrm{CuO}, \mathrm{Ag}, \mathrm{Pd}, \mathrm{Cu}\right.$, and $\left.\mathrm{PdO}\right)$. Copper nanoparticles lack catalytic properties for the growth of carbon nanotubes. Copper-copper bonds are weaker than carbon-carbon bonds and copper nanoparticles do not have the energy necessary to break down carbon bonds and therefore, carbon nanotubes cannot be formed. Silver nanoparticles embedded in silicon exhibit higher thermal stability, thereby allowing for a more extensive range of applications. However, when they are treated as a bed of palladium, nanocatalysts play a significant role in improving the catalytic properties of palladium nanoparticles [26]. In a chemical vapor deposition system, copper and silver nanoparticles refine penetration of carbon into palladium nanocatalysts, and carboncarbon bonds in carbonic gas are broken faster, resulting in more nanotubes being formed.

It is found that the median diameter of the nanotubes has a non-monotonous dependence on the thickness of the catalytic nanoparticle layer. This dependence suggests the competence of several mechanisms in the growth of the CNTs. 


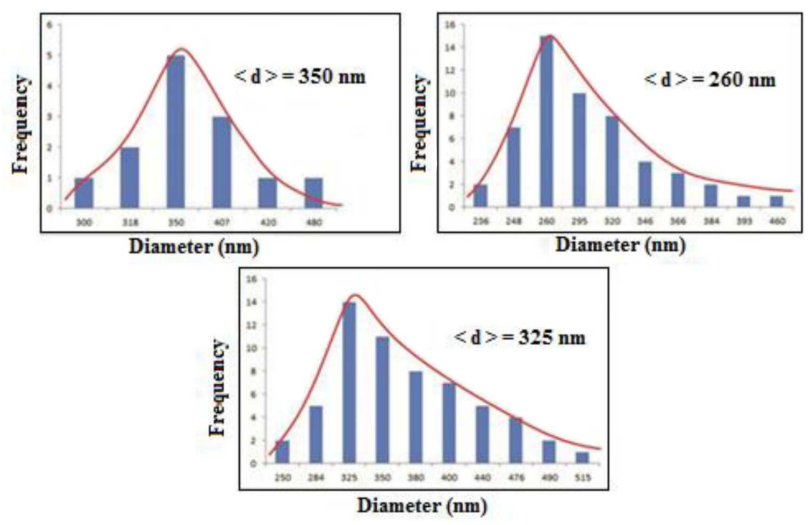

Fig. 4. Histograms of diameter distribution of produced CNTs at different thicknesses of catalytic layers: (a) $\# 1$, (b) $\# 2$, and (c) \#3.

It is visible from the SEM images that the density of carbon nanotubes in the sample with a thickness of $34.8 \mathrm{~nm}$ (sample 1) is considerably lower in comparison with the other samples. Thus, the density of the active nucleation sites is lower compared to the other two experiments. As a consequence, the carbon atoms obtained from the decomposition of the carbonic gas (acetylene) are distributed in less formed nanotubes and, in turn, more separated from each other, resulting in CNTs that tend to grow wider and shorter than in the other samples.

The density of carbon nanotubes in the sample with a thickness of $40 \mathrm{~nm}$ (sample 2) is much higher than in the previous one (Fig. 3b). Therefore, by increasing the thickness of the catalytic nanoparticle layer in a completely identical growth condition, carbon nanotubes are grown in more nucleation sites. It is observed that in some parts of this sample, more nanotubes are formed. Catalytic particles are probably more active in these parts. In the sample with a thickness of $46 \mathrm{~nm}$ (sample 3), the size of the catalytic nanoparticles is larger, producing wider and longer CNTs than these in sample 2 (Fig. 3c).

Figure 5 shows the Raman spectrum of sample 3 . The band that appears in the $1500-1605 \mathrm{~cm}^{-1}$ and $1250-1450 \mathrm{~cm}^{-1}$ regions are attributed to the $G$-band and $D$-band, respectively. The $G$ and $D$ bands are associated to the vibration frequency of the carbon material with the orbital structures of $S P^{2}$ and the disorderinduced vibration of the $\mathrm{C}-\mathrm{C}$ band [1], respectively. In the Raman spectra, there are three main peaks. The first two main peaks at $1361 \mathrm{~cm}^{-1}$ and $1579 \mathrm{~cm}^{-1}$ are, respectively, related to $G$ and $D$ bands representing the graphitized MWCNTs formation and the disorder carbon presence due to defects in the graphene-like hexagonal disordered carbons, respectively. It should be noted that the peak located at $1800 \mathrm{~cm}^{-1}$ is related to the laser. The peak intensity ratio $I(G) / I(D)$ is a supplementary mark for the quality of carbon nanotubes due to the relative response of the graphite carbon to defective carbon, and this peak intensity ratio for sample 3 is 1.06. Thus, synthesized carbon nanotubes have good

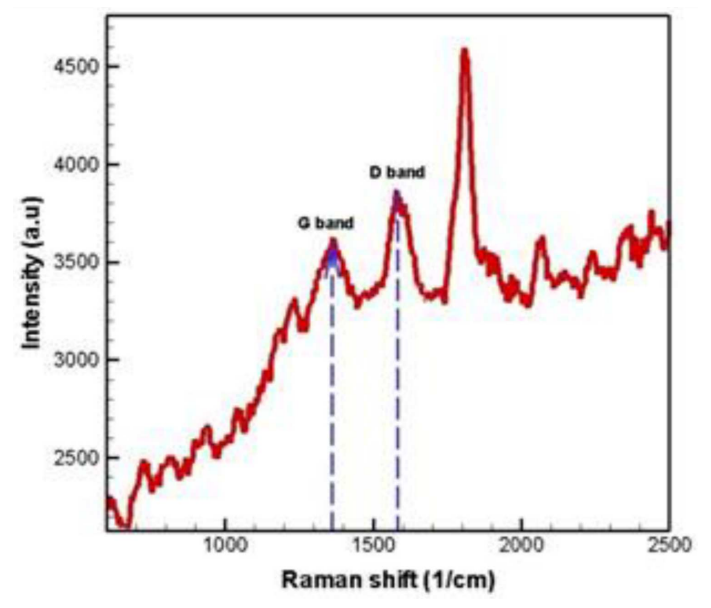

Fig. 5. Raman spectrum of typical synthesized CNTs (sample\#3).

structural qualities. The absence of a peak in the range $100-300 \mathrm{~cm}^{-1}$ (radial breathing modes, RBM) confirms the growth of multi-walled nanotubes. Although multiwalled nanotubes also produce weak RBMs, these modes cannot be detected by the Raman spectroscopy.

\section{Conclusion}

Based on previous studies [24, 25], we have prepared catalytic copper-silver-palladium thin films using sputtering techniques. These films are constituted by nanocrystals of different phases $\left(\mathrm{Cu}_{2} \mathrm{O}, \mathrm{CuO}, \mathrm{Ag}, \mathrm{Pd}\right.$, $\mathrm{Cu}$, and $\mathrm{PdO}$ ), whose combination produce the nucleation of the CNTs. SEM and Raman analyses indicate that the produced CNTs are multiwalled with a diameter that depends on the thickness of the nanocatalytic layers. Using a film with a thickness of $34.8 \mathrm{~nm}$ as catalytic surface, lower density of CNTs were obtained. These nanotubes grow wider, with a median diameter of $350 \mathrm{~nm}$, and shorter. When the thickness of the copper-silverpalladium thin films were increased to 40 and $46 \mathrm{~nm}$, the density of the active nucleation sites is increased and multi-walled CNTs with good structural quality are produced, whose diameters are 260 and $325 \mathrm{~nm}$, respectively.

\section{Acknowledgments}

The authors would like to thank Dr. Carlos Luna, Universidad Autónoma de Nuevo León, Mexico, for his helpful advice and stimulating discussions during this study.

\section{References}

[1] M. Akbarzadeh Pasha, M. Ranjbar, M.A. Vesaghi, A. Shafiekhani, Appl. Surf. Sci. 257, 1511 (2010).

[2] C. Journet, W.K. Maser, P. Bernier, A. Loiseau, M. Lamy de La Chapelle, S. Lefrant, P. Deniard, R. Lee, J.E. Fischer, Nature 388, 756 (1997).

[3] A. Thess, R. Lee, P. Nikolaev, H. Dai, P. Petit, J. Robert, C. Xu, Y. Hee Lee, S. Gon Kim, A.G. Rinzler, Science 273, 483 (1996). 
[4] H. Li, C. Shi, X. Du, C. He, J. Li, N. Zhao, J. Mater. Lett. 62, 1472 (2008).

[5] J. Talat, M. Sabzi, B. Safibonab, I. Hasanzadeh, A. Arman, I. Karimzadeh, J. Nanosci. Nanotechnol. 18, 1110 (2018)

[6] M. Akbarzadeh Pasha, A. Shafiekhani, M.A. Vesaghi, Appl. Surf. Sci. 256, 1365 (2009).

[7] S. Rezaee, A. Ghaderi, A. Boochani, S. Solaymani, Res. Phys. 7, 3640 (2017)

[8] M. Akbarzadeh Pasha, R. Poursalehi, M.A. Vesaghi, A. Shafiekhani, Physica B Condens. Matter 405, 3468 (2010).

[9] B.Q. Wei, R. Vajtai, P.M. Ajayan, Appl. Phys. Lett. 79, $1172(2001)$.

[10] B. Gao, C. Bower, J.D. Lorentzen, L. Fleming, A. Kleinhammes, X.P. Tang, L.E. McNeil, Y. Wu, O. Zhou, Chem. Phys. Lett. 327, 69 (2000)

[11] H. Ago, K. Nakamura, S. Imamura, M. Tsuji, Chem. Phys. Lett. 391, 308 (2004).

[12] J. Grunes, J. Zhu, G.A. Somorjai, Chem. Commun. 18, 2257 (2003)

[13] M.M. Moreno R. Pleixats, Acc. Chem. Res. 36, 638 (2003).

[14] A. Roucoux, J. Schulz, H. Patin, Chem. Rev. 102, 3757 (2002)

[15] S.Y. Lee, M. Yamada, M. Miyake, Sci. Technol. Adv. Mater. 6, 420 (2005).
[16] Y.M. Wong, S. Wei, W.P. Kang, J.L. Davidson, W. Hofmeister, J.H. Huang, Y. Cui, Diam. Relat. Mater. 13, 2105 (2004).

[17] Y. Zhao, Y.X. Pan, L. Cui, C. Liu, Diam. Relat. Mater. 16, 229 (2007)

[18] R.K. Joshi, M. Yoshimura, C.C. Chiu, F.K. Tung, K. Ueda, K. Tanaka, J. Phys. Chem. C 112, 1857 (2008).

[19] Y. Sun, H. Hau Wang, M. Xia, J. Phys. Chem. C 112, 1250 (2008).

[20] A. Ahmadpourian, C. Luna, A. Boochani, A. Arman, A. Achour, S. Rezaee, S. Naderi, Europ. Phys. J. Plus 131, 381 (2016).

[21] S. Rezaee, Res. Phys. 9, 1521 (2018).

[22] Ş.Ţălu, S. Solaymani, M. Bramowicz, S. Kulesza, A. Ghaderi, S. Shahpouri, S.M. Elahi, J. Mater. Sci. Mater. Electron. 27, 9272 (2016).

[23] P.K. Stoimenov, R.L. Klinger, G.L. Marchin, K.J. Klabunde, Langmuir 18, 6679 (2002).

[24] S. Rezaee, N. Ghobadi, Res. Phys. 9, 1148 (2018).

[25] N. Ghobadi, S. Rezaee, J. Mater. Sci. Mater. Electron. 27, 8464 (2016).

[26] N. Narayan, A. Meiyazhagan, R. Vajtai, Materials 12 , 3602 (2019) 